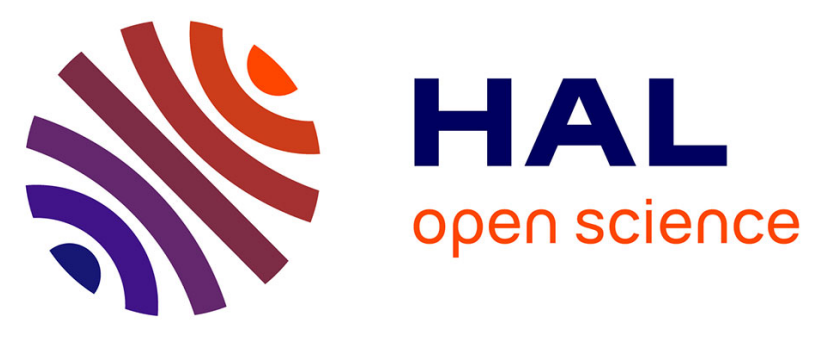

\title{
Leaching effect on mechanical properties of cement-aggregate interface
}

Mouad Jebli, Frédéric Jamin, Céline Pelissou, Etienne Malachanne, Eric Garcia-Diaz, Moulay Saïd El Youssoufi

\section{- To cite this version:}

Mouad Jebli, Frédéric Jamin, Céline Pelissou, Etienne Malachanne, Eric Garcia-Diaz, et al.. Leaching effect on mechanical properties of cement-aggregate interface. Cement and Concrete Composites, 2018, 87, pp.10 - 19. 10.1016/j.cemconcomp.2017.11.018 . hal-01772568

\section{HAL Id: hal-01772568 \\ https://hal.science/hal-01772568}

Submitted on 20 Apr 2018

HAL is a multi-disciplinary open access archive for the deposit and dissemination of scientific research documents, whether they are published or not. The documents may come from teaching and research institutions in France or abroad, or from public or private research centers.
L'archive ouverte pluridisciplinaire HAL, est destinée au dépôt et à la diffusion de documents scientifiques de niveau recherche, publiés ou non, émanant des établissements d'enseignement et de recherche français ou étrangers, des laboratoires publics ou privés. 


\title{
Leaching effect on mechanical properties of cement-aggregate interface
}

\author{
M. Jebli a, c, *, F. Jamin ${ }^{\text {a, b }}$, C. Pelissou ${ }^{\text {b, d }}$, E. Malachanne ${ }^{\text {c }}$, E. Garcia-Diaz ${ }^{\text {c }}$, \\ M.S. El Youssoufi ${ }^{\mathrm{a}, \mathrm{b}}$ \\ a LMGC, Univ. Montpellier, CNRS, Montpellier, France \\ ${ }^{\mathrm{b}}$ MIST Lab., IRSN, CNRS, Univ. Montpellier, France \\ ${ }^{\mathrm{c}} \mathrm{C} 2 \mathrm{MA}$, Ecole des Mines D'Alès, Alès, France \\ d Institut de Radioprotection et de Sûreté Nucléaire IRSN, B.P. 3, 13115 Saint-Paul-lez-Durance Cedex, France
}

\section{A B S T R A C T}

This study concerns the characterization of the mechanical properties of the cement paste and of the cement-aggregate interface in the degraded state by a chemical leaching mechanism. This study is carried out within the framework of the MIST laboratory. The experimental tests were carried out on cement paste and composites consisting of aggregates bound by the same cement paste prepared with a water/cement ratio of 0.5 . The particular experimental devices, designed and produced for the purposes of this study, made it possible to directy solicit the composites at the cement-aggregate interface. As the process of leaching with the deionized water occurs very slowly, the experimental study is accelerated in the laboratory by replacing water by ammonium nitrate solution. To quantify the development and ki-netics of chemical degradation at the cemented bond, the concrete leaching fronts are characterized at different times of degradation by using phenolphthalein. The local mechanical tests (tensile and shear) are performed on cement paste and composite at different degradation rate. The experimental results show a fast drop in shear or tensile strength of about $45 \%$ at the beginning of degradation. These results confirm the effect of the cement paste-aggregate interface degradation on the mechanical properties.

Keywords:

Cement paste

Cement-aggregate interface

Chemical degradation

Leaching

Tensile test

Shear test

Local scale

\section{Introduction}

The concrete is a porous and heterogeneous material filled with a interstitial solution in thermodynamic equilibrium with solid hydrates. The interstitial solution contained in the porous structure of the cement paste is highly charged with alkaline $\left(\mathrm{Na}^{+}, \mathrm{K}^{2+}, \mathrm{Ca}^{2+}\right.$, $\mathrm{OH}^{-}$) [20]. Those ions contribute to the chemical equilibrium. The contact of the concrete with water creates concentration gradients in the interstitial solution between the outside environment and the core of the concrete. This gradient causes the development of a degraded zone in the cement paste and the diffusion of calcium in the interstitial solution toward the aggressive solution. Moreover, this diffusion perturbs the established equilibrium between the interstitial solution and solid phases and leads to the dissolution or precipitation of the solid phases. The decrease in the concentration of calcium in this zone induces the dissolution of Portlandite and

\footnotetext{
* Corresponding author. LMGC, Univ. Montpellier, CNRS, Montpellier, France. E-mail address: mouad.jebli@umontpellier.fr (M. Jebli).
}

the progressive decalcification of C-S-H. The consequences on the cement paste microstructure are an increase of porosity which has important consequences to transport and a decline of the mechanical properties of the cementitious material with time: a loss of elastic properties and a loss of strength $[6,8,15]$.

Several studies have been conducted on cement paste and mortar leaching at macroscopic scale $[1,2,6,8,16,19]$. The local hydration conditions in the areas close to the paste-aggregate interface are altered at the beginning of the reactions. This change is due to the presence of an excess of water due to either the wall effect or to the bleeding. These two phenomena lead to a local increase of the pores volume in which the hydrates can be developed. It is well known that the porosity of the cement-aggregate interface is always greater than the porosity in the bulk paste. So, this higher prorosity increases the dissolution rate of portlandite and decalcification of C-(A-)S-H and, consequently, accelerated the chemical attack front at the interface. On the other hand, the presence of aggregates influences the diffusion rate, the aggregates slow down the transport of the material due to the increase of tortuosity [17]. 
demonstrated that the effective diffusion coefficient of concrete decreases with the aggregate content until it reaches about 50\% [18]. carried out accelerated leaching tests on cement paste, mortar and concrete to highlight the aggregate effect on the leaching kinetics. Comparing the degradation of cement paste and concrete, the results showed that the presence of aggregate constitutes an obstacle on the pathway of the material transport in the cement paste, which slows down the calcium ions diffusion process, and may introduce additional tortuosity. Until now, few studies concerned the effect of the cement-aggregate interface in the literature. To characterize the leaching effect of the cement-aggregate interface on the mechanical properties of cementitious materials, a set of experiments were conducted by Carde and François [5] on cement paste and mortar, with or without silica fume. The addition of silica fume allows the consumption of portlandite by the pozzolanic reaction to form $\mathrm{C}-\mathrm{S}-\mathrm{H}$, thus densifying the microstructure and leading to interface reduction [9]. For samples containing silica fume, it has been shown that there is little difference in strength between cement paste and mortar. This in particular may be explained by properties of the interface which approximate those of the paste. In the case of samples without silica fume, there is a greater loss of strength of the mortar compared to that of the cement paste. Indeed, this is due to the high concentration of the portlandite at the interphase. The preferential leaching of this hydrate causes a considerable reduction of the mechanical properties. An attempt at a direct characterization of the leaching effect of the interface was carried out by Buzzi et al. [4]. They subjected rockconcrete composites to accelerated leaching using ammonium nitrate with concentration of $6 \mathrm{~mol} / \mathrm{l}$ for a period of 100 days, at the end of which shear tests were performed. It has been shown that a degradation of a depth of about $2 \mathrm{~mm}$ produces a radical change in behavior due to the local loss of mechanical properties. In a recent experimental study at local scale [12], submitted composites, consisting of two spherical aggregates bonded by a cement paste, to accelerated leaching by ammonium nitrate. These samples were subjected to direct tensile tests which solicit the cement-aggregate interface at different time of degradation. They have a fast drop in the force at rupture at the beginning of degradation.

In this paper, we propose to characterize at the same local scale the leaching effect of the cement-aggregate interface on the mechanical properties by considering two original geometric configurations of composites samples. The composites are subjected to direct tensile and shear tests after accelerated leaching.

\section{Experimental program}

The aim of this experimental study is to characterize the effect of the chemical degradation by leaching on the mechanical behavior of pure cement paste and of cement paste-aggregate interface. This is achieved using direct tensile and direct shear tests, on the same samples and the same mechanical tests as proposed by Jebli et al. [13].

\subsection{Geometric configuration of the samples}

The tests were carried out on prismatic composite samples. This composite consisting of limestone aggregates and cement paste. The geometry of the samples is the same as that defined by Jebli et al. [13] (Fig. 1), to study the mechanical behavior of cement paste and cement paste-aggregate interface during hydration. The same materials are also chosen, as summarized in Table 1.

The chemical composition of the cement used is shown in Table 2, and the diffractogram of the limestone aggregate is presented in Fig. 2. The diffractogram shows that this limestone is very rich in calcite $\left(\mathrm{CaCO}^{3}\right)$, and we also find very little quartz.

The composites are prepared using special molds (Fig. 3), with a constant distance between the agregate in the case of composite for tensile tests. After preparation, the composites are removed after $24 \mathrm{~h}$ from the molds and conditioned 40 days in water saturated with lime.

\subsection{Mechanical test}

As shown in Fig. 4, the mechanical tests (direct tensile and direct shear tests) are performed with the mechanical devices detailed in Jebli et al [13]. The tests (tensile and shear tests) are performed with the MTS machine at a constant loading speed of $0.01 \mathrm{~mm} / \mathrm{s}$. For the direct tensile test (Fig. 4a), the sample is fixed to the machine by means of the rods. During the tensile test, the force $F$ is measured and the stress $\sigma$ is calculated (Equation (1)). For the direct shear test

Table 1

Material data of components used.

\begin{tabular}{ll}
\hline Aggregate & \\
Type & Limestone (Madeleine quarry) \\
Dimension & $10 \times 10 \times 10 \pm 0.5 \mathrm{~mm}^{3}$ \\
Density & $2722 \mathrm{~kg} / \mathrm{m}^{3}$ \\
Cement paste & \\
Formula & CEM II/B-LL $32.5 \mathrm{~N}$ \\
Water/Cement ratio & 0.5 \\
\hline
\end{tabular}

Table 2

Chemical composition of cement.

\begin{tabular}{llllll}
\hline Oxyde & $\mathrm{CaO}$ & $\mathrm{SiO}_{2}$ & $\mathrm{Al}_{2} \mathrm{O}_{3}$ & $\mathrm{Fe}_{2} \mathrm{O}_{3}$ & $\mathrm{SO}_{3}$ \\
\hline Mass percentage(\%) & 56.8 & 20.2 & 6.9 & 3.9 & 2.9 \\
\hline
\end{tabular}

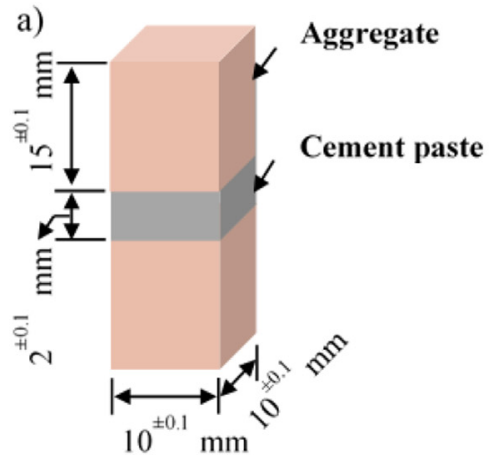

b)

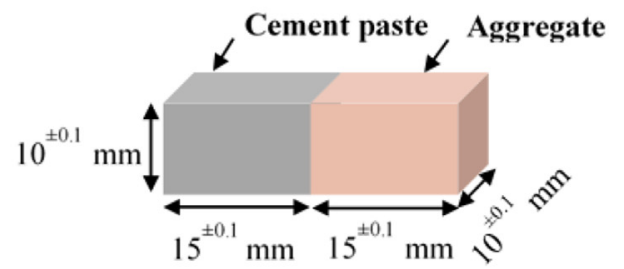

Fig. 1. Sample sizes for direct tensile tests a) and direct shear tests b). 


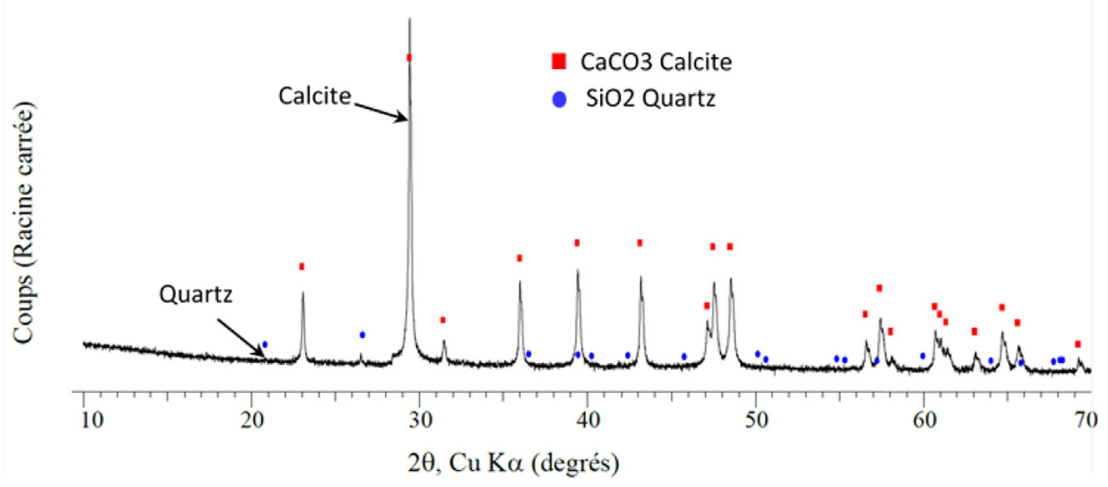

Fig. 2. Diffractogram of the limestone sample.
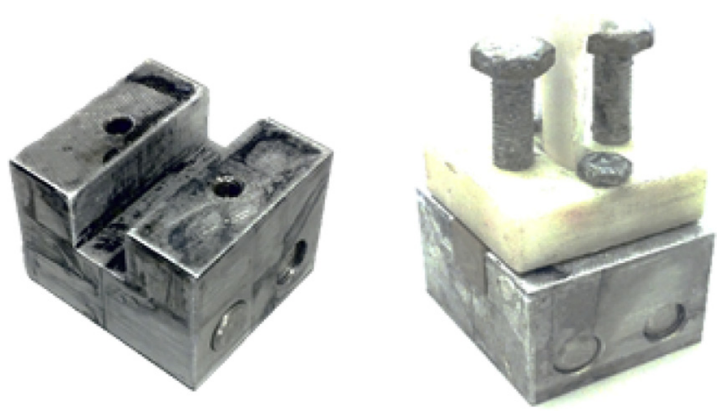

Fig. 3. Pictures of molds used in composites manufacturing.

(Fig. 4b), the device test consists of two metal boxes and screws to apply a normal force $N$. This force is measured by means of a force sensor (LCMKD $200 \mathrm{~N}$ ) set at the rear of the sample. During the shear test, the force $T$ is measured and the stress $\tau$ is calculated (Equation (1)). The displacement, although imposed during the tests (tensile or shear tests), is corrected by the results of the image correlation [7,13].

The relations between the variables are:

$\sigma=\frac{F}{S_{0}} ; \tau=\frac{T}{A^{\prime}} ; \sigma_{s}=\frac{N}{A^{\prime}}$

where $S_{0}$ is the initial section of the sample and $A^{\prime}$ the corrected contact section of the cement paste/aggregate during the shear test.

a)

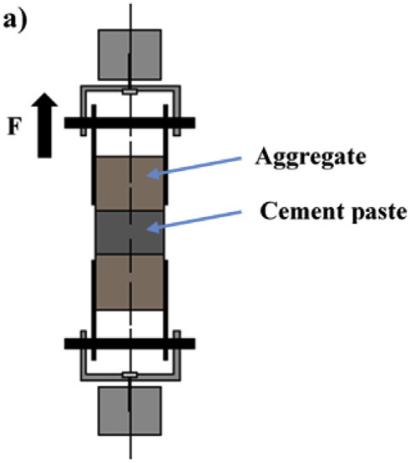

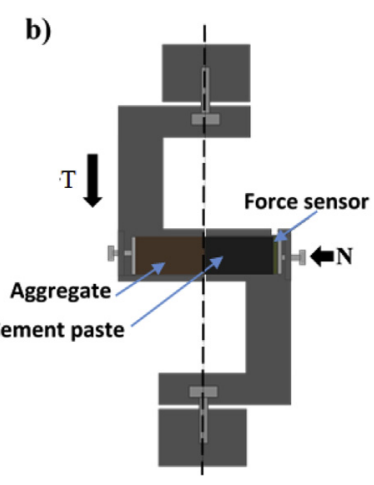

Fig. 4. Experimental devices for direct tensile test a) and direct shear test b).

\section{Leaching process}

The objective of this experiment is to analyze the effect of chemical degradation on the mechanical properties at the scale of cement-aggregate interface.

Leaching of a cement paste specimen by water implies a very slow process of chemical degradation. It is then necessary, for laboratory experiments, to use techniques to accelerate this phenomenon. The degradation by ammonium nitrate $\left(\mathrm{NH}_{4} \mathrm{NO}_{3}\right)$ was chosen by several authors $[3,6,11,14,16,19]$ : it causes a degradation similar to that observed during pure water leaching, but with a shorter characteristic time. This degradation method consists of immersing the samples in the ammonium nitrate solution with a concentration of $480 \mathrm{~g} / \mathrm{l}$. The characterization method with indicator dye was chosen to identify the degraded thickness of composites. This method has been successfully used and validated by several authors $[16,18]$....

After 40 days of storage in lime water to limit the dissolution of the cement paste and to protect them from the effects of early drying, the composites are immersed in an ammonium nitrate solution. During the leaching process, the $\mathrm{pH}$ of the solution is monitored (Fig. 5).

The volume of solution is sufficiently high so no new solution has been added during the test. At different degradation times (respectively 1, 6, 24, 48, 72, 96 and $101 \mathrm{~h}$ ), the samples were removed from the ammonium nitrate solution and then placed in another container with pure water for one day for rinsing. After the rinsing step, the degradation depth can be measured (phenolphthalein test) on the samples and the mechanical tests can be performed (Fig. 4).

To ensure the contact of the solution with all the lateral surfaces of the prismatic composites, the samples are vertically placed in the container (Fig. 6).

Nguyen et al. [18] has shown that limestone aggregate is not stable in a $6 \mathrm{~mol} / \mathrm{l}$ solution of ammonium nitrate. To eliminate any effect of aggregate degradation, a first experiment of accelerated degradation of the aggregates used, has been carried out. The purpose of these tests is to observe and analyze qualitatively the effects of chemical degradation and leaching kinetics of aggregates. At different degradation times, the mass and size of the aggregates are controlled. The test carried out on the aggregates shows that these aggregates are stable over the duration of our tests, a short duration of $101 \mathrm{~h}$ compared to the 142 days-long tests by Nguyen et al. [18] concerning to the ammonium nitrate solution.

In order to demonstrate the effect of the degradation of the interface on the mechanical properties, the results of the degraded cement paste are compared with that of the composites. The 


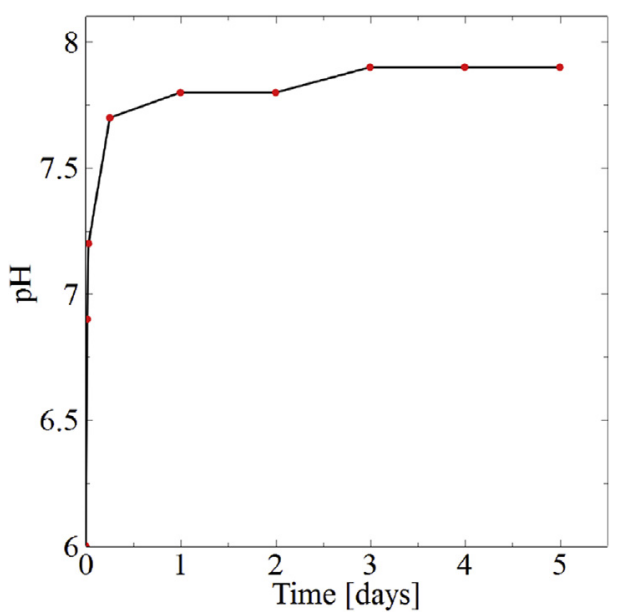

Fig. 5. Evolution of pH during degradation by ammonium nitrate.

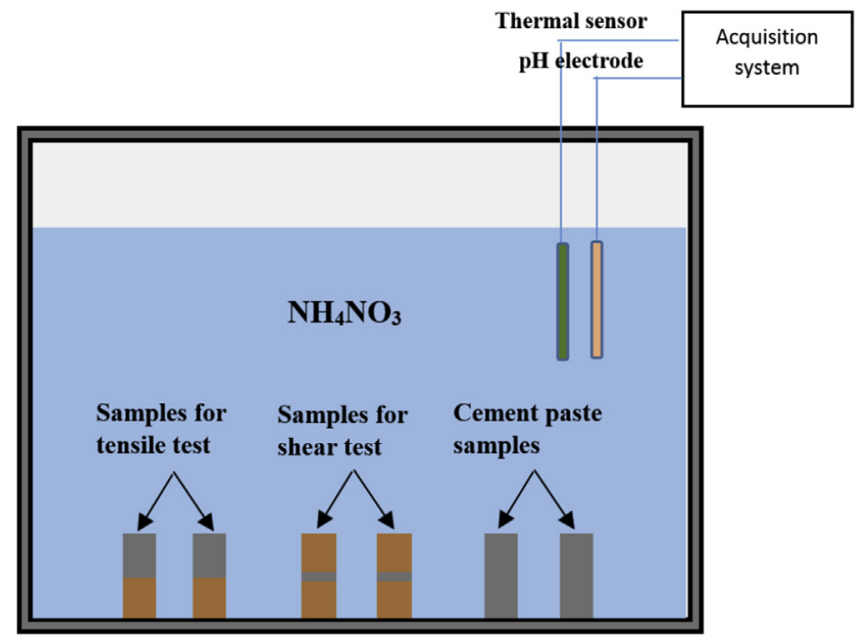

Fig. 6. Scheme of the leaching test of samples under ammonium nitrate solution $(6 \mathrm{~mol} / \mathrm{l})$.

cement paste samples are exposed to the same chemical degradation. The upper and lower parts of the samples are covered with an adhesive tape that is not reactive with the solution (Fig. 7) in order to protect the support.

During all the period of the test, the degradation thickness of the sample is regularly measured. To be characterized, the sample is polished to the center with a polisher (Fig. 7).
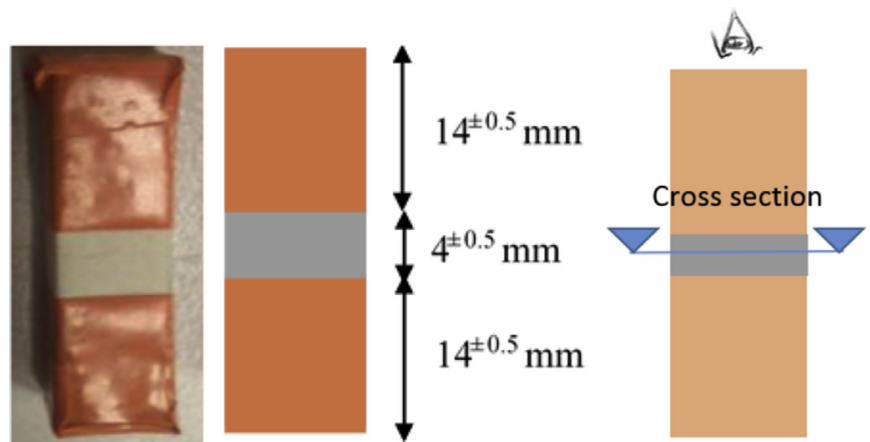

Fig. 7. Picture of isolated cement paste samples and scheme illustrating sample cuts.
The phenolphthalein is then injected onto the cross-section of the cement paste and composites. After a few seconds, two distinct zones can be observed: a pink zone corresponding to the sound zone and a gray zone color corresponding to the degraded zone. The measurement of the degradation thickness can be carried out $24 \mathrm{~h}$ after the application of phenolphthalein. We performed four samplings at six degradation times $(1,6,24,48,72$ and $96 \mathrm{~h})$ to measure the degraded thickness. Some illustrations are shown in Fig. 8 for different degradation times. Fig. 8 shows an increase of degraded area with the increase in degradation time.

After spraying the phenolphthalein, the measurements of the degradation thickness were made on three samples at each degradation time. Four measurements on each sample are made from the edge. The mean value of the degraded thickness is retained. The diagram of the method for measuring the degraded thickness $(e)$ is illustrated in Fig. 9.

Fig. 10 shows an evolution of the average degraded thickness of cement paste and composite as a function of the immersion time in ammonium nitrate expressed as a square root of time. Fig. 10 shows a similar linear evolution of the degraded average thickness $(e)$ measured on both types of sample as a function of the square root of the immersion time in the aggressive solution of $\mathrm{NH}_{4} \mathrm{NO}_{3}$ : a slope of 2 is deduced, similar results have been obtained by Tognazzi [19] and Heukamp et al. [10].

For each degradation time, the sound surface $S_{s}$ is measured and the degraded surface $S_{d}=S_{0}-S_{s}$, where $S_{0}$ is the initial surface, is deduced therefrom. The surfaces are calculated in the transverse direction of the samples as shown in Fig. 9.

In order to analyze the degradation influence on the mechanical properties, a degradation rate $\delta$ is defined: it corresponds to the ratio of the degraded surface $S_{d}$ by the initial surface $S_{0}$ :

$\delta=\frac{S_{d}}{S_{0}}=\frac{S_{0}-S_{s}}{S_{0}}=\frac{e(10-e)}{25}$

where $e$ (in $\mathrm{mm}$ ) is the degraded thickness.

SEM tests were also performed to visualize the degraded

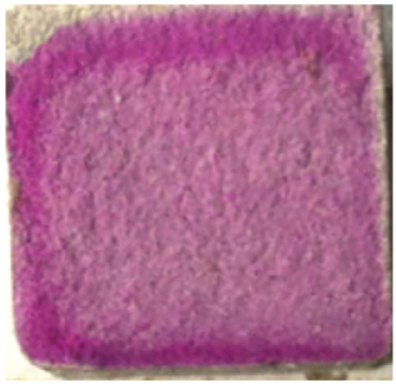

Sound

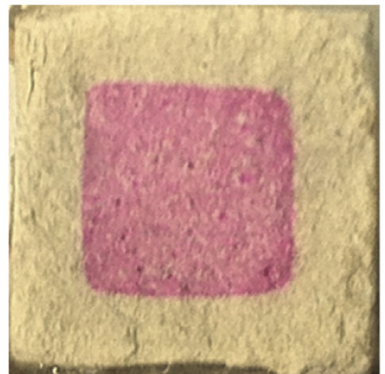

24 hours

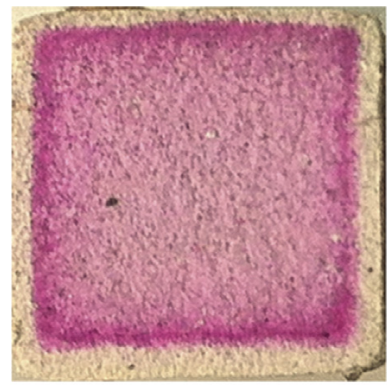

6 hours

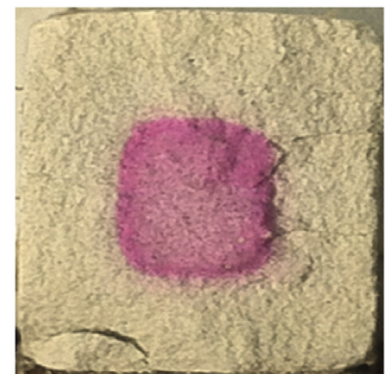

72 hours
Fig. 8. Measurement of degraded thickness using phenolphthalein, on samples having undergone respectively $0,6 \mathrm{~h}, 24 \mathrm{~h}, 72$ h chemical degradation by $\mathrm{NH}_{4} \mathrm{NO}_{3}$. 


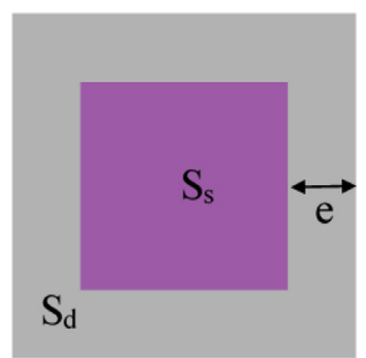

Fig. 9. Scheme of the measuring method of degraded thickness. Note that the value of the measured thickness is corrected thereafter, multiplying by a correction coefficient of 1.17 [16]; because the phenolphthalein does not give the exact position of the dissolution front of portlandite.

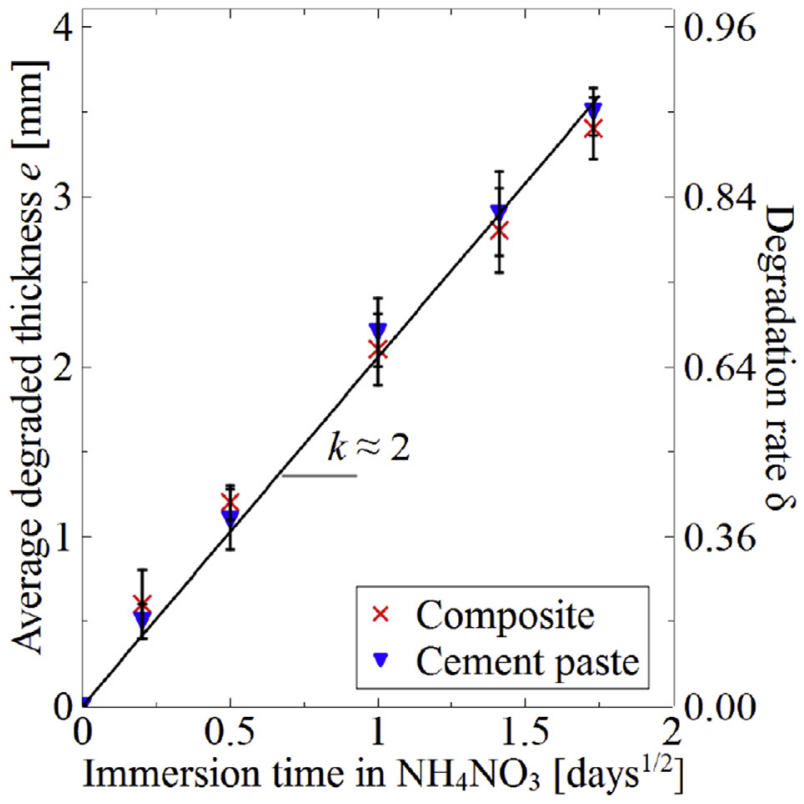

Fig. 10. Evolution of the degraded thickness as a function of the square root of the immersion time in ammonium nitrate.

thickness at this scale. The composites must be prepared very carefully to visualize the cement paste-aggregate interface. The samples were immersed in epoxy resin. The degraded samples are fragile and break easily that make their preparation difficult, therefore the degraded thickness at the cement-aggregate interface can not be measured. Fig. 11 shows an example of a SEM image (Quanta 200 Feg: Vacuum pressure) of a sound and degraded sample for a degradation rate of $\delta=0.2$.

\section{Mechanical tests}

In this section, we present some results obtained in mechanical tests, tensile and shear on sound samples (reference) and on samples chemically degraded by leaching. At each chemical degradation time interval, the prismatic samples were subjected to direct tensile and shear tests (respectively for $6,24,48,72,96$ and $101 \mathrm{~h}$ ). The tests were carried out on composites and on cement paste alone to highlight the effect of the chemical degradation at cement-aggregate interface. The displacement, although imposed during the tests, is corrected by the results of the image correlation $[7,13]$.

\subsection{Direct tensile tests}

The sound and degraded samples, with three samples at each degradation rate, were subjected to the direct tensile test to measure their strengths. Fig. 12 shows the stress - strain curves for the cement paste and the composite.

Fig. 12 shows a decrease of the strength $\sigma_{r}$ and of the Young's modulus $E_{t}$ with the increase in degradation rate for both samples. At the beginning, the decrease is more pronounced for the composite than for the cement paste. A quasi-brittle behavior is observed at each degradation rate. The evolution of the strengths is then plotted as a function of the degradation rate in order to demonstrate the effect of the leaching with ammonium nitrate. Fig. 13 shows the evolution of the average tensile strength $\sigma_{r}$ as a function of degradation rate $\delta$. The standard deviation is calculated from the results of three tests at each degradation rate.

It is noted a decrease of strength with increasing degradation. The ratio of the resistance of the composite to the strength of cement paste as a function of the degradation rate is shown in Fig. 14 in order to demonstrate the effect of the presence of the interphase on the mechanical properties.

A very considerable loss of composite strength is observed at the beginning of degradation ( $\delta=0.2)$, a loss of about $45 \%$ in the case of composites whereas a loss of $30 \%$ in the case of the cement paste. This fact reinforces the idea that the cement-aggregate interphase is more sensitive to degradation than the cement paste due to the higher porosity at the interphase. This porosity increases the diffusion of the ions to the exterior, thereafter accelerates the degradation in this zone. These results confirm the results of Jebli et al. [12] obtained by tensile tests on composites degraded by accelerated leaching $\left(\mathrm{NH}_{4} \mathrm{NO}_{3} 6 \mathrm{M}\right)$ but with spherical aggregates.

The Young's modulus, denoted $E_{t}$, is calculated from the linear slope of stress-strain curves. Fig. 15 shows the average of Young's modulus as a function of the degradation rate for the tensile tests. A similar decrease in the Young's modulus is observed for both sample types.

The linear behavior up to rupture and the quasi-fragile fracture allow us to calculate the critical energy from the following relation [13].

$W_{t}(\delta)=\frac{1}{2} \times \frac{\left(\sigma_{r}(\delta)\right)^{2}}{E_{t}(\delta)}$

where $\sigma_{r}(\delta)$ is the strength at degradation rate $\delta$ and $E_{t}(\delta)$ is Young's modulus in tensile test at degradation rate $\delta$.

Fig. 16 shows the evolution of the average critical energy as function of the degradation rate $\delta$ for the cement paste samples and for the composite samples.

There is a decrease of the critical energy with the evolution of degradation. This decrease has a similar trend as the decrease of strength for both materials. For the composites, a fast decrease in energy is also observed after a degradation rate of $\delta=0.2$.

\subsection{Direct shear tests}

In order to evaluate the local mechanical behavior of the degraded material, three prismatic composites were subjected to direct shear tests. The results of the shear tests on the partially degraded composites are compared with the results of the sound material. The same tests on the cement paste were carried out also to demonstrate the effect of the degradation of the cementaggregate interface on the mechanical properties at shear test.

Fig. 17 shows stress - strain curves at different stages of chemical degradation during shear tests, without normal stress $\sigma_{s}$, for both 

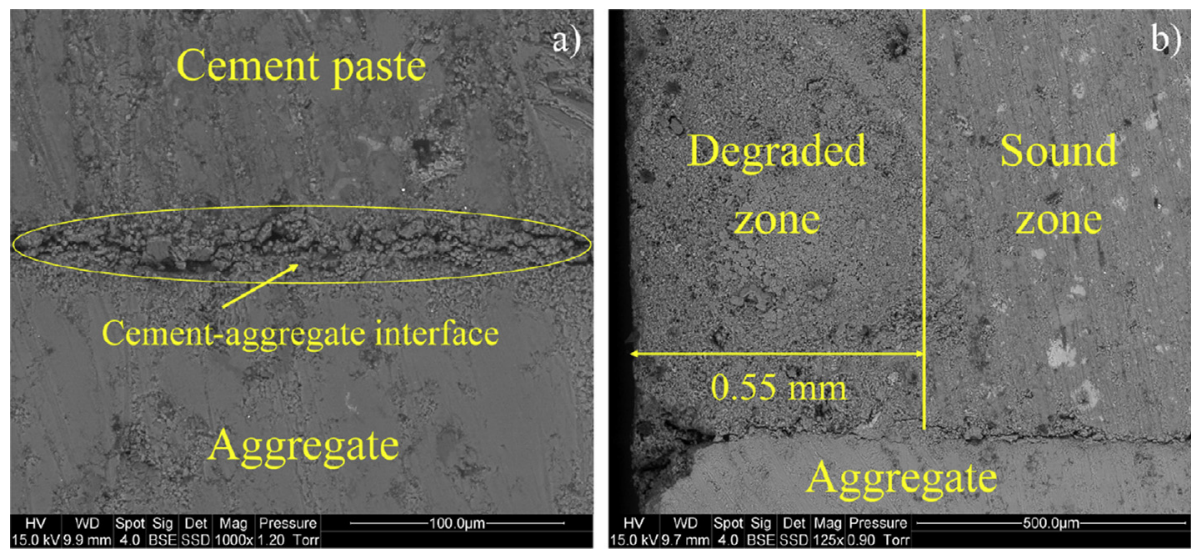

Fig. 11. SEM image in BSE mode of a sound sample a) and degraded after for a degradation rate of $\delta=0.2 \mathrm{~b}$ ).
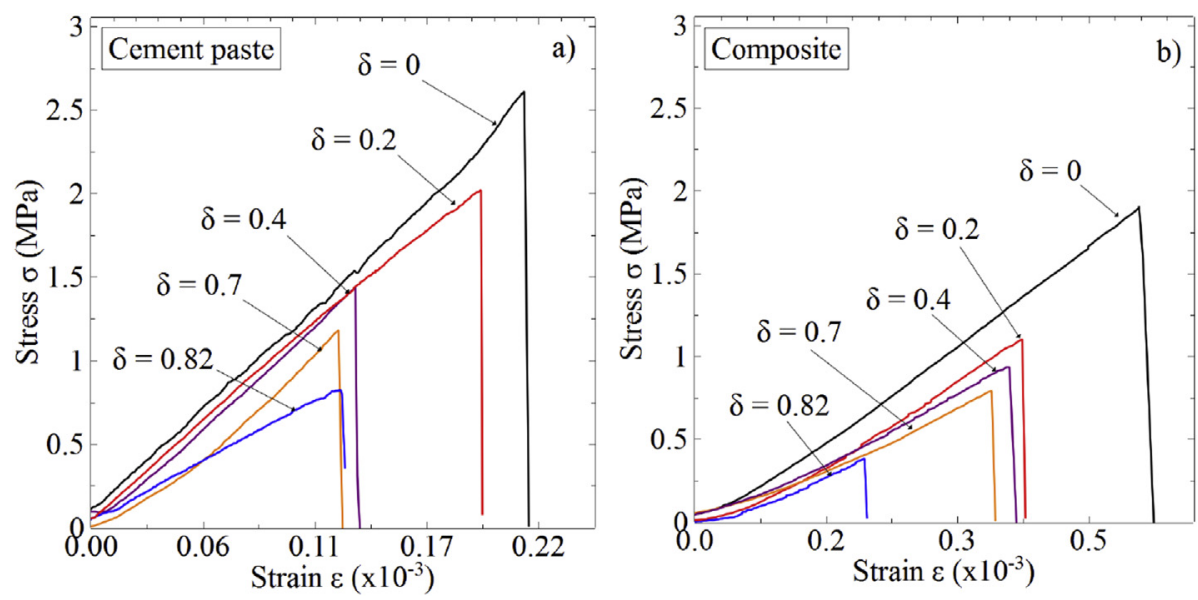

Fig. 12. Behavior in direct tensile test of sound samples and partially degraded of cement paste a) and composite b).
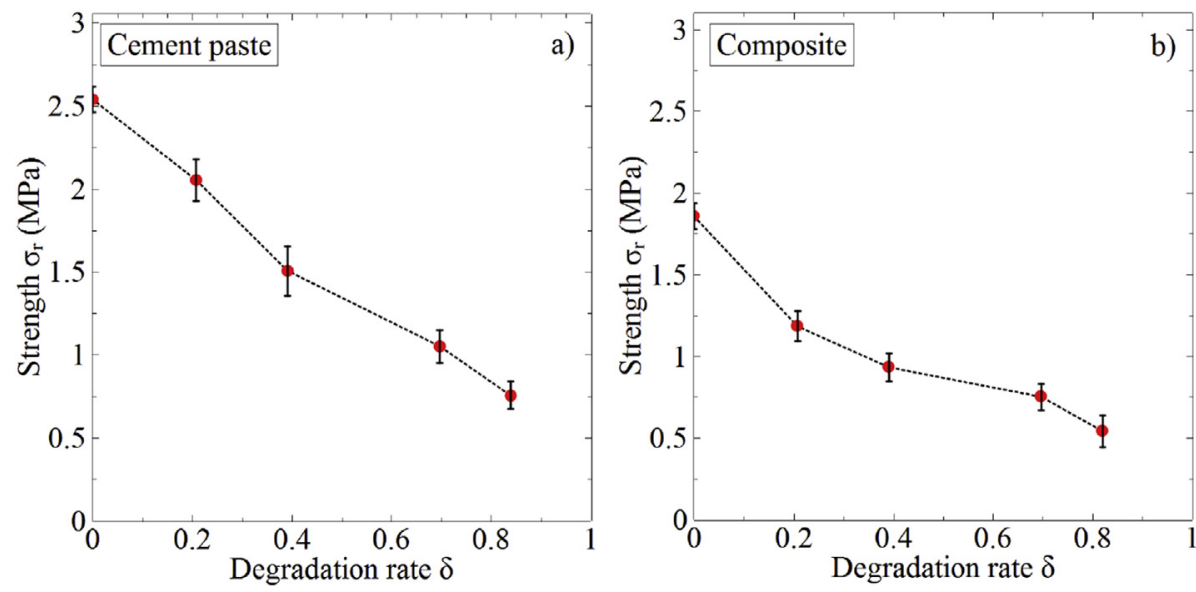

Fig. 13. Evolution of the tensile strength $\sigma_{r}$ as a function of the degradation rate of cement paste a) and composite b).

types of sample (cement paste and composite). A quasi-brittle behavior also is observed at the case of the shear test. The values of the average shear strength $\tau_{r}$ and the standard deviation three tests at each degradation rate as a function of the degradation rate $\delta$ for the shear tests are presented in Fig. 18.

By observing these results, a decrease in the tensile stress and the tangential modulus is observed when the degradation increases for the composite and the cement paste. As for the tensile test, there is a rapid drop in the resistance of the composite for a degradation rate of $\delta=0.2$. Beyond this rate, the rate of loss of mechanical properties decreases and tends towards a constant. On the other hand, in the case of cement paste, a gradual decrease in mechanical properties is observed with increasing degradation rate. 


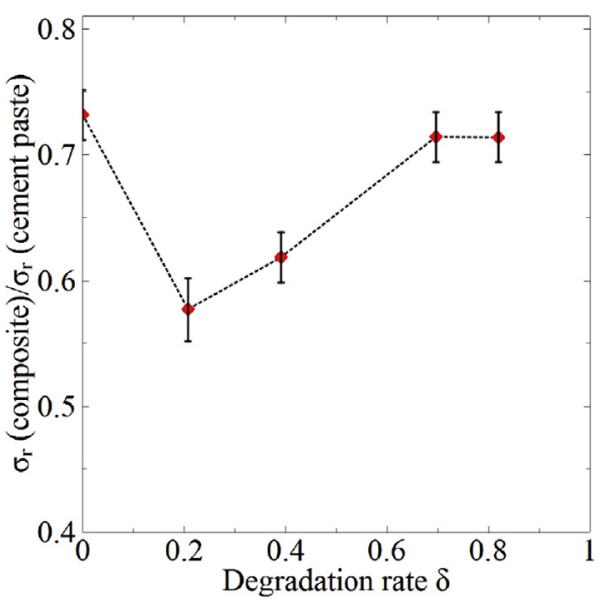

Fig. 14. Evolution of the ratio $\sigma_{r}$ (composite)/ $\sigma_{r}$ (cement paste) as a function of the degradation rate.

The critical energy is also calculated for the shear test in the same way as for the tensile test (Equation (3)). Fig. 19 shows a decrease in average critical energy $W_{s}$ with increasing degradation time. The evolution of critical energy is similar for both materials (cement paste and composite), with higher values of the cement paste than that of the composites.

After the characterization of the effect of degradation on the shear stress respectively for pure cement paste and the composite "cement paste-aggregate", we are interested in the effect of the normal stress $\sigma_{s}$ on the shear strength $\tau_{r}$ of previously degraded samples. The degraded samples are subjected to direct shear tests at different normal stresses. The obtained results are presented in Fig. 20 for different confinement stresses $\left(\sigma_{s}=0 ; 0.5 ; 1 ; 1.5 \mathrm{MPa}\right)$, expressing the average shear strength at 40 days of hydration (denoted $\tau_{r}(40)$ ) as a function of the normal stress applied. For the sake of clarity, some results of the degradation rate are represented.

A linear increase in the shear stress $\tau_{r}$ (stress at peak value) is observed with the application of the normal stress for both types of samples. The slope is less steep when the degradation time increases. This evolution allows to represent by the Mohr-Coulomb criterion (Equation (4)), and to deduct the local friction angle $\phi$ and the local cohesion $c$ at each degradation rate.

$\tau_{r}=\sigma_{s} \times \tan (\phi)+c$

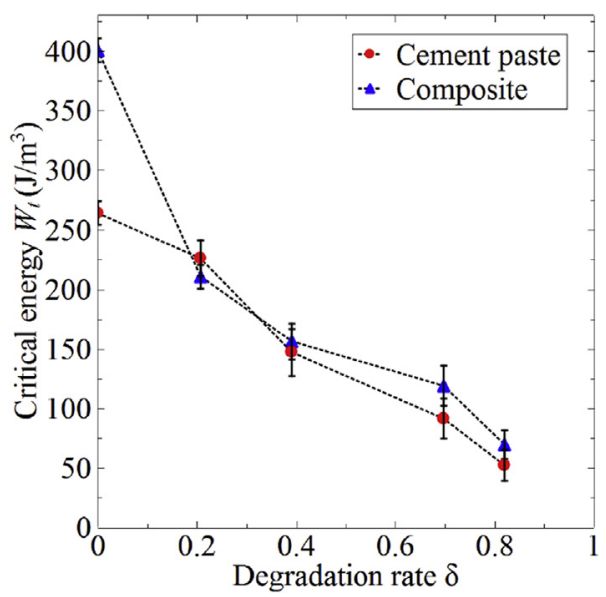

Fig. 16. Evolution of the critical energy as a function of the degradation rate during the tensile test.

Fig. 21 shows the evolution of local friction angle and local cohesion as a function of degradation rate.

The local friction angle and cohesion decrease with increasing of degradation rate. In the case of the composite, the angle of friction and the cohesion decreases fastly at degradation rate $\delta=0.2$. On the other hand, in the case of cement paste, the local friction angle does not vary much at the beginning of the degradation $(\delta=0.2 ; 0.4)$. Beyond $\delta=0.4$, the two curves follow the same pattern.

\section{Discussion}

Leaching of cement-based materials by deionized water leads to a degradation of mechanical properties. This chemical attack induces a complete leaching of the portlandite and a progressive decalcification of the C-S-H. Due to the slow leaching kinetics obtained using deionized water, an accelerated process (using the $\mathrm{NH}_{4} \mathrm{NO}_{3}$ solution) was carried out on composites and on cement paste at the scale of the cement-aggregate interface in order to demonstrate the effect of leaching on the mechanical properties. Similar leaching results are obtained for the degraded thickness at various samples (cement paste and composite). The cementaggregate interface degradation could not be observed with phenolphthalein due to the small thickness of this zone. Thus, the results of the leaching presented here are those of the cement paste that binds the aggregates. As has been shown above, all the facies of
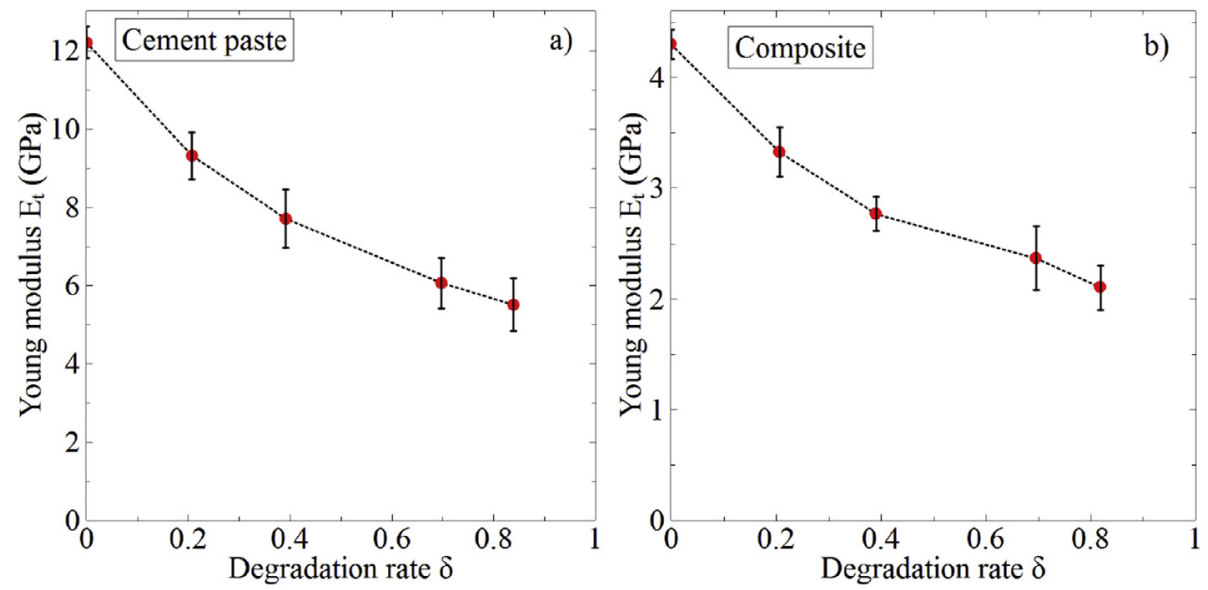

Fig. 15. Evolution of the Young modulus $E_{t}$ as a function of the rate of degradation of cement paste a) and composite b). 

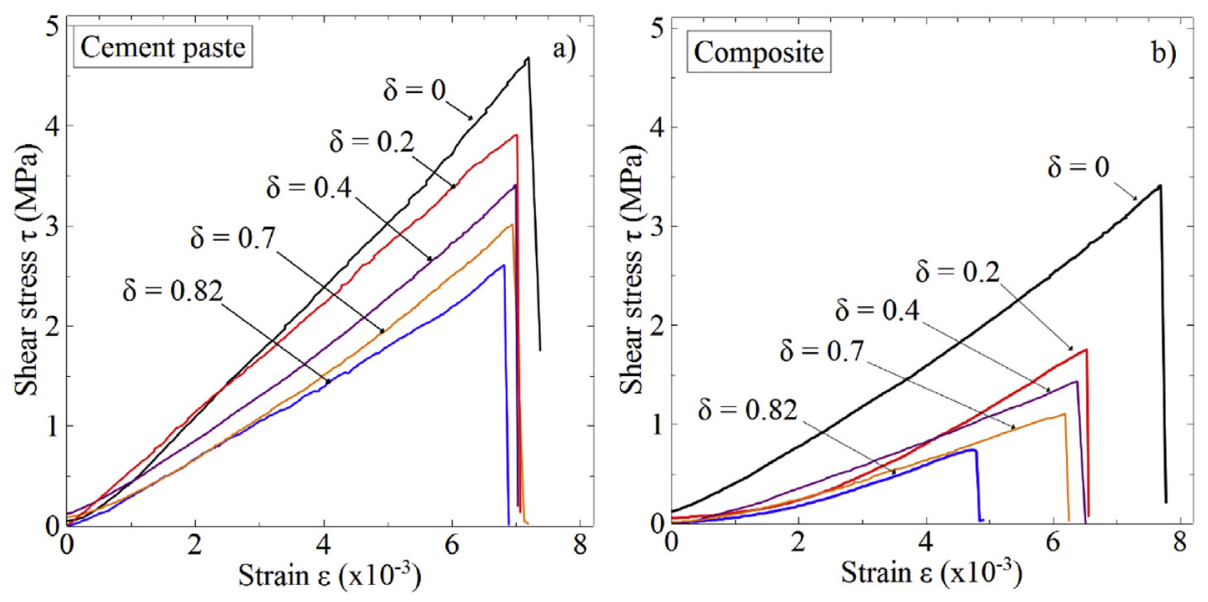

Fig. 17. Behavior in direct shear test of sound samples and partially degraded of cement paste a) and composite b).
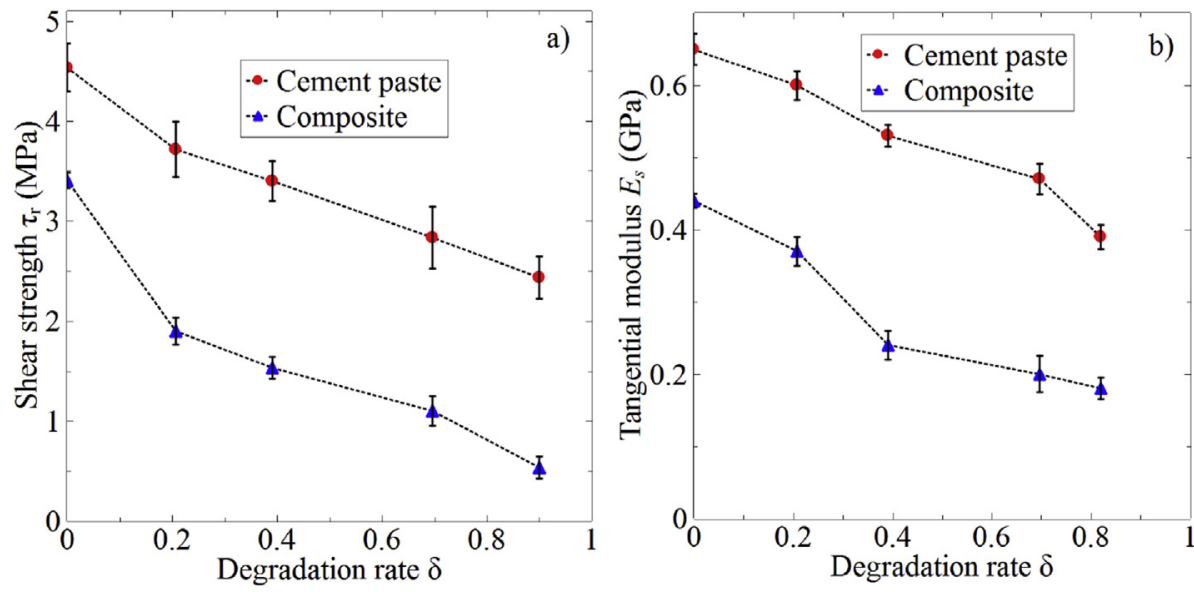

Fig. 18. Evolution of the strength $\tau_{r}$ a) and tangential modulus $E_{S}$ b) as a function of the degradation rate of cement paste and composite.

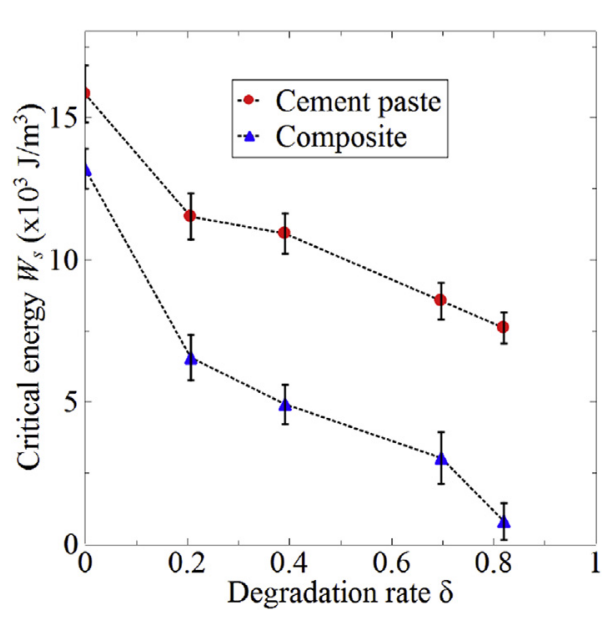

Fig. 19. Evolution of the critical energy as a function of the degradation rate during the shear test.

rupture of the tensile tests and shear tests show that the loss of cohesion occurs at the cement-aggregate interface. Moreover, tensile and shear tests on the composites showed a very fast decrease in strength at the beginning of leaching $(\delta=0.2)$, which was not observed in the case of cement paste. This suggests that the degradation kinetics is faster at the cement-aggregate interface, occurring a loss of cohesion, resulting in more significant degradation of mechanical properties.

This phenomenon could not be observed on a macroscopic scale for which leaching kinetics appears to be faster for cement paste than for concrete. Several authors attribute this effect to the tortuosity of concrete, which is a limiting factor in the diffusion of ammonium nitrate ions. At the scale of the composites studied in this work, the effect of tortuosity can not be considered.

\section{Conclusion}

Most experimental studies concerning the effect of leaching on the mechanical properties of cementitious materials have been carried out on a macroscopic scale and to a lesser extent on a mesoscopic scale. The work proposed here constitutes a contribution to the study of the effects of leaching at the scale of cementaggregate interface. These effects are described using direct tensile and direct shear tests at this scale.

The mechanical tensile test allowed us to characterize the cement-aggregate interface of composites. The results showed a considerable decrease in the tensile strength from the onset of degradation. The comparison of the results of the tensile test on the cement paste and on the composite confirmed this observation. In the case of cement paste, a more progressive decline in strength 

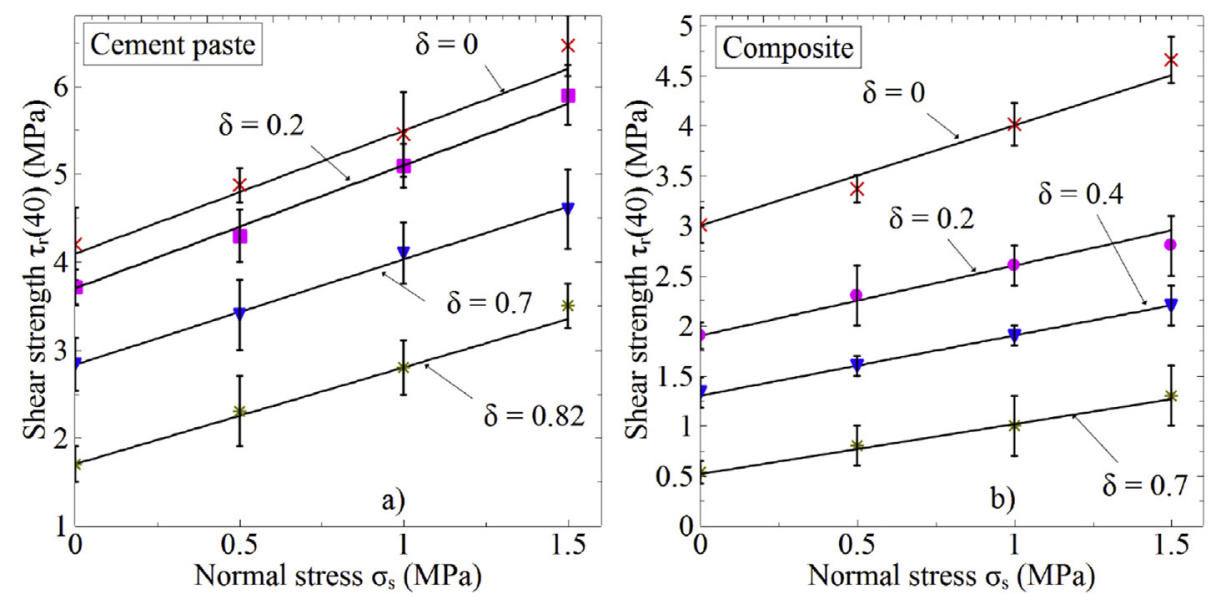

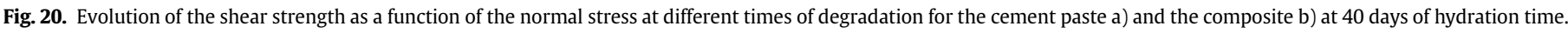
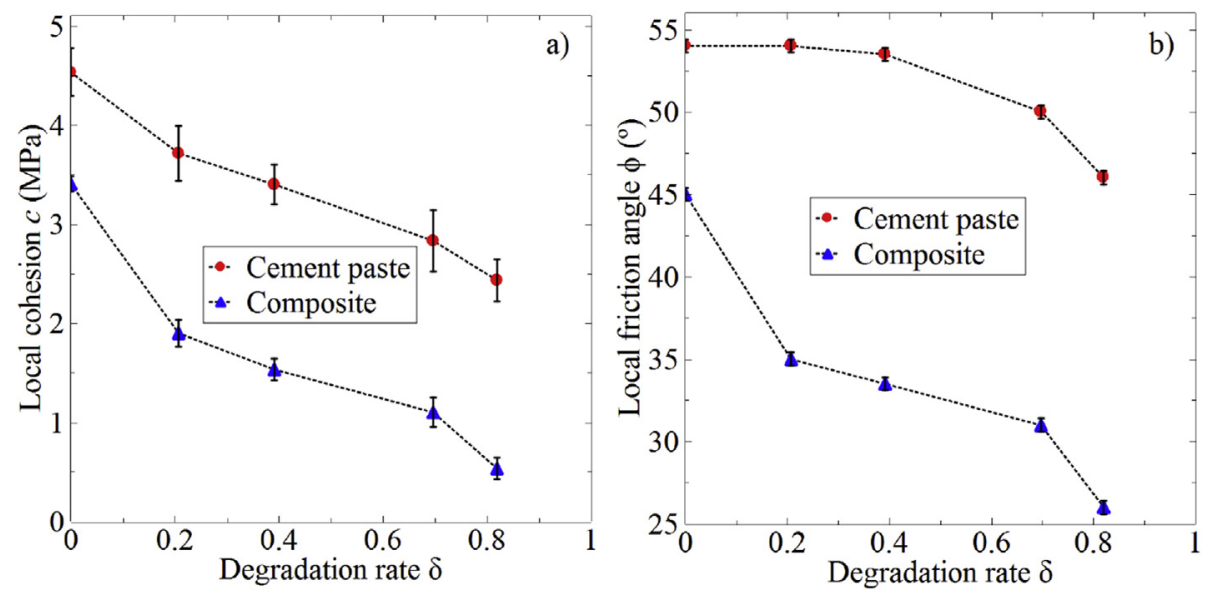

Fig. 21. Evolution of the local cohesion a) and local friction angle b) as a function of the degradation rate $\delta$.

with the increase of degradation time is observed.

The results of the direct shear test confirmed the trend observed during the tensile test. The results showed a fast drop in shear strength at the beginning of leaching. The increase in the normal stress at each degradation rate shows the evolution of the local friction angle and local cohesion with the increase of the degradation. The evolution involves a decrease in the local friction angle. This suggests that increasing the porosity of the cement-aggregate interface changes the contact surface state between the cement paste and the aggregate. The friction angle decrease is more prononced in the case of composites compared to cement paste. This suggests that leaching kinetics is faster in the presence of interfaces, which are clearly more sensitive to degradation. The interface can be attributed to higher porosity and portlandite concentration in this area. This high porosity accelerates the phenomenon of ions diffusion, and thus constitutes a preferential leaching vector of the portlandite, which is more abondant in this zone. The reaction leads to a fast loss of adhesion between the aggregates and the cement paste, as a consequence of a fast degradation of the mechanical properties of the composites.

\section{References}

[1] F. Adenot, M. Buil, Modelling of the corrosion of the cement paste by deionized water, Cem. Concr. Res. 22 (1992) 489-496.

[2] B. Bourdette, E. Ringot, J. Ollivier, Modelling of the transition zone porosity,
Cem. Concr. Res. 25 (1995) 741-751.

[3] N. Burlion, D. Bernard, D. Chen, X-ray microtomography: application to microstructure analysis of a cementitious material during leaching process, Cem. Concr. Res. 36 (2006) 346-357.

[4] O. Buzzi, M. Boulon, M. Hervé, K. Su, Leaching of rock-concrete interfaces, Rock Mech. Rock Eng. 41 (2008) 445-466.

[5] C. Carde, R. François, Effect of the leaching of calcium hydroxide from cement paste on mechanical and physical properties, Cem. Concr. Res. 27 (1997) $539-550$.

[6] C. Carde, R. Francois, J. Torrenti, Leaching of both calcium hydroxide and csh from cement paste: modeling the mechanical behavior, Cem. Concr. Res. 26 (1996) 1257-1268.

[7] A. Chrysochoos, B. Wattrisse, J.-M. Muracciole, Y. El Kaïm, Fields of stored energy associated with localized necking of steel, J. Mech. Mater. Struct. 4 (2009) 245-262.

[8] B. Gerard, G. Pijaudier-Cabot, C. Laborderie, Coupled diffusion-damage modelling and the implications on failure due to strain localisation, Int. J. Solids Struct. 35 (1998) 4107-4120.

[9] O.E. Gjorv, P.J. Monteiro, P.K. Mehta, Effect of condensed silica fume on the steel-concrete bond, Mater. J. 87 (1990) 573-580.

[10] F. Heukamp, F.-J. Ulm, J. Germaine, Mechanical properties of calcium-leached cement pastes: triaxial stress states and the influence of the pore pressures, Cem. Concr. Res. 31 (2001) 767-774.

[11] F.H. Heukamp, F.-J. Ulm, J.T. Germaine, Poroplastic properties of calciumleached cement-based materials, Cem. Concr. Res. 33 (2003) 1155-1173.

[12] M. Jebli, F. Jamin, E. Garcia-Diaz, M. El Omari, M.S. El Youssoufi, Influence of leaching on the local mechanical properties of an aggregate-cement paste composite, Cem. Concr. Compos. 12 (2016) 241-250.

[13] M. Jebli, F. Jamin, E. Malachanne, E. Garcia-Diaz, M.S. El Youssoufi, Experimental characterization of mechanical properties of the cement-aggregate interface in concrete, in: Powders and Grains 2017 8th International Conference on Micromechanics on Granular Media, 2017, p. 12014. EDP Sciences volume 140. 
[14] S. Kamali, M. Moranville, S. Leclercq, Material and environmental parameter effects on the leaching of cement pastes: experiments and modelling, Cem. Concr. Res. 38 (2008) 575-585.

[15] B. Larbi, W. Dridi, P. Dangla, P. Le Bescop, Link between microstructure and tritiated water diffusivity in mortars: impact of aggregates, Cem. Concr. Res. 82 (2016) 92-99.

[16] C. Le Bellégo, Couplages chimie-mécanique dans les structures en béton attaquées par l'eau: étude expérimentale et analyse numérique, Ph.D. thesis École normale supérieure de Cachan, 2001.

[17] A. Lobet, M. Cubaynes, J. Ollivier, A new testing method for determining chloride diffusion coefficient, in: Int. Conf. On Performance of Construction Materials in the New Millenium (ICPCM), Cairo (Egypt), 2003, pp. 469-477.

[18] V. Nguyen, H. Colina, J.M. Torrenti, C. Boulay, B. Nedjar, Chemo-mechanical coupling behaviour of leached concrete: Part i: experimental results, Nucl. Eng. Des. 237 (2007) 2083-2089.

[19] C. Tognazzi, Couplage fissuration-dégradation chimique dans les matériaux cimentaires: caractérisation et modélisation, Ph.D. thesis, INSA, Toulouse, 1998.

[20] A. Vollpracht, B. Lothenbach, R. Snellings, J. Haufe, The pore solution of blended cements: a review, Mater. Struct. 49 (2016) 3341-3367. 